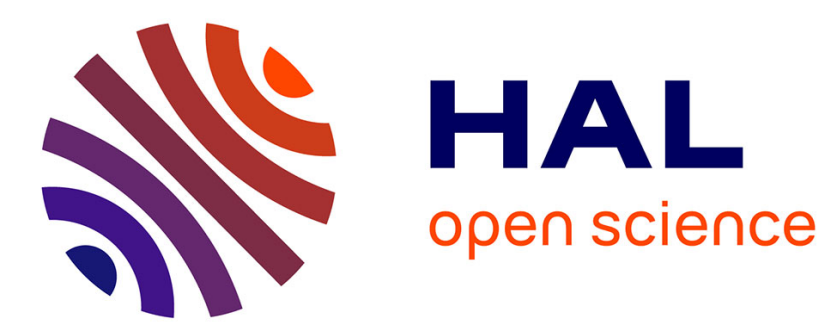

\title{
Connecting Mediterranean Countries through Electricity Corridors: New Institutional Economic and Regulatory Analysis
}

Haikel Khalfallah

\section{- To cite this version:}

Haikel Khalfallah. Connecting Mediterranean Countries through Electricity Corridors: New Institutional Economic and Regulatory Analysis. Utilities Policy, 2015, 32, pp.45-54. 10.1016/j.jup.2015.01.001 . hal-01111432

HAL Id: hal-01111432

https://hal.univ-grenoble-alpes.fr/hal-01111432

Submitted on 30 Jan 2015

HAL is a multi-disciplinary open access archive for the deposit and dissemination of scientific research documents, whether they are published or not. The documents may come from teaching and research institutions in France or abroad, or from public or private research centers.
L'archive ouverte pluridisciplinaire HAL, est destinée au dépôt et à la diffusion de documents scientifiques de niveau recherche, publiés ou non, émanant des établissements d'enseignement et de recherche français ou étrangers, des laboratoires publics ou privés. 


\title{
ÉCONOMIE DU DÉVELOPPEMENT DURABLE ET DE L'ÉNERGIE
}

\section{Connecting Mediterranean Countries through Electricity Corridors \\ New Institutional Economic and Regulatory Analysis}

\section{Haikel Khalfallah}

\author{
Janvier 2015
}

Cahier de recherche EDDEN $n^{\circ} 1 / 2015$ 



\title{
Connecting M editerranean Countries through E lectricity C orridors: New Institutional Economic and Regulatory Analysis
}

\section{H aikel K halfallah}

Associate Professor, EDDEN-UPM F, +33 4565285 80, haikel.khalfallah@ upmf-grenoble.fr

\begin{abstract}
A super grid connecting the two shores of the M editerranean could help Europe meet its targets for integrating renewable energy. This paper assesses the business models for building a platform for wholesale renewable energy trade via electricity corridors linking the two regions of the M editerranean basin. We demonstrate that the optimal framework for designing the corridor project is a long-term contractual agreement to coordinate bilaterally the necessary investments. Furthermore a hybrid governance structure requiring only limited regulatory adaptation seems to be the most efficient structure for facilitating investment in the corridor's infrastructure.
\end{abstract}

Keywords: New Institutional Economics, Renewable Energy Sources, Regulation.

JE L Classification: L 14, L51, Q27

\section{Introduction}

Under the terms of the K yoto Protocol, the European Union (EU) is committed to reduce overall greenhouse gas emissions of its M ember States by $20 \%$ by 2020 compared to 1990 levels. For 2050, EU M ember States have also endorsed the goal of reducing the U nion's greenhouse gas emissions by $80 \%$ to $95 \%$ compared to 1990 levels $s^{1}$. L arge sums have been spent in recent years to encourage local renewable-energy projects in Europe. However, in order to completely decarbonize the EU energy system, additional options and solutions will be needed. In particular, there has been lively debate about the need to build a super grid ${ }^{2}$ connecting the two shores of the M editerranean basin ${ }^{3}$ (B attaglini et al. 2009). Not only would European countries benefit from such infrastructure, but $N$ orth A frican

\footnotetext{
1 "The Roadmap for moving to a competitive low carbon economy in 2050" (COM/2011/112) adopted by the Commission proposes to extend these objectives to 2050.

${ }^{2} \mathrm{~A}$ super grid is a high-voltage transmission infrastructure designed for long-distance transmission of electricity connecting remote systems which may have different characteristics.

${ }^{3}$ T wo super-grid projects are currently under study. Desertec, a consortium looking at the technical and economic feasibility of creating an interconnected electricity network reaching from $\mathrm{N}$ orth A frica to the $\mathrm{M}$ iddle East, and crossing southern Europe, which would supply $15 \%$ of EU electricity consumption by 2025 . M edG rid aims to explore the feasibility of investing in $20 \mathrm{GW}$ renewable capacity in the south and east of the $M$ editerranean region. $5 \mathrm{GW}$ would be exported to the $\mathrm{EU}$.
} 
countries would also benefit, with scope for improving the efficiency of their system and enjoying access to more diverse energy sources.

The two regions desire to achieve at least two common energy goals in the near future. The first is security of supply. Conventional energy sources constitute a substantial part of the energy mix of most EU countries ${ }^{4}$. A predominant share of energy is imported from outside Europe. North A frican countries also rely heavily on such energy sources to fuel their power plants (Bugaje, 2006). Even if this energy, primarily natural gas, is sourced locally and readily available in the short and medium terms, it is accepted that this resource will become rare in the long term and should be used for purposes other than generating electricity, as more climate-friendly alternatives can be developed to sustain security of supply. B oth regions are therefore seeking alternative energy sources.

The second joint goal, following on from the first, relates to the climate-policy targets that the two regions have established and should attain in the near future. Successive EU directives and regulations ${ }^{5}$ have set a mandatory target designed to ensure that the U nion meets its ambitious climate and energy targets by 2020 . Similar targets have been set in some $\mathrm{N}$ orth A frican countries, including M orocco, A lgeria and Tunisia (B rand and Zingerle 2011; K omendantova et al. 2012), emphasizing the need to invest more in renewable energy as well as facilitate its deployment and integration.

The complementarity between systems north and south in terms of market conditions and, in particular, energy mix would reinforce the opportunities for interconnection infrastructure. System complementarity is more apparent when looking at the energy resource mix characterizing the two regions. On the one hand scope for using renewable resources to generate electricity in $\mathrm{N}$ orth A frica is much greater than in the EU. Sunlight is twice as powerful as in France or Germany, for instance ${ }^{6}$. W ind speeds are much higher too. On the other hand, the energy mix in Europe is more varied than in North A frica. At present the energy mix south of the M editerranean depends mainly on gas and fuel

\footnotetext{
${ }^{4}$ In $201344 \%$ of the generation mix in ENTSO-E members countries was provided by fossil fuels, $26 \%$ by nuclear power, $18 \%$ by hydro and $13 \%$ by other renewable (ENTSO-E 2014).

${ }^{5}$ N otably Directive 2009/28/EC of the European Parliament and the Council of 23 A pril 2009 on promoting the use of energy from renewable sources.

${ }^{6} \mathrm{Dr}$ Gerhard K nies, a German physicist and founder of the Trans-M editerranean Renewable Energy Cooperation (TREC) network of researchers says that: "The world's deserts collect more energy from the sun in six hours than mankind consumes in an entire year."
} 
oil (Bugaje, 2006), whereas the EU uses nuclear power, coal, and hydropower to diversify the energy mix.

This review of common energy-policy objectives and system complementarity suggests that both regions would gain from building energy infrastructure to link the two sides of the Mediterranean. Such infrastructure would facilitate investment in renewable energy in North Africa. Given the region's significant potential in terms of solar and wind energy (Battaglini et al, 2009; K omendantova et al, 2012), the EU could achieve its target by importing such energy on a large scale from North A frica ${ }^{7}$. D emand in North A frica is relatively low compared to its renewable resource potential. Thus, after covering local needs, the surplus could be exported to Europe. Support from European investment funds would facilitate such a large capital outlay, without requiring massive support by national authorities or local investors in the region's difficult financial context ${ }^{8}$. Furthermore such infrastructure would facilitate wholesale trade in energy between the two regions, primarily renewable energy as explained above. Some regulatory constraints will nevertheless need to be removed ${ }^{9}$, as discussed in the following sections, in order to facilitate such trade. Lastly, thanks to this infrastructure, supply security would be increased and dependence on fossil fuels would be decreased. Traditional energy sources are currently either contracted with controversial partners such as Russia, in the case of the $\mathrm{EU}$, or becoming increasingly scarce, as with natural gas in A lgeria, so they are no longer the preferred choice in the energy mix.

This paper aims to assess, from the point of view of $\mathrm{New}$ Institutional Economics and regulation, the optimal business model for connecting the two shores of the M editerranean via electricity corridors. The electricity corridor would comprise two investment facilities: an interconnector linking the two shores of the M editerranean; and the renewable power plants, which are al ready available or need to build to cater to local and European demand. The focus is on the export potential of the renewable

\footnotetext{
${ }^{7}$ The technical success of such a huge programme would however depend on the ability of the European electricity network to accommodate large electricity imports from $N$ orth $A$ frica (B rancucci $M$ artínez-A nido et al. 2013). We note that the analysis disregards the technical issue of the super grid.

${ }^{8} \mathrm{~N}$ otably in Tunisia, a problem which is has become more acute since the revolution of spring 2011.

${ }^{9} \mathrm{~N}$ ote that the politic instability of $\mathrm{N}$ orth $\mathrm{A}$ frican countries is a geopolitical risk which could influence the longterm viability of the project.
} 
supplies that $\mathrm{N}$ orth A frica could offer Europe as an additional option for decarbonizing the EU energy system over the long term. Given N orth A frica's considerable renewable-energy potential, establishing an optimal regulatory framework would encourage capital investment, creating a win-win situation for both regions. Demand in North Africa could be completely covered by power generated from renewable sources. The EU would benefit from the residual energy to achieve its own climate policy objectives. On the assumption that substantial investments will be made in renewable energy in $\mathrm{N}$ orth A frica, it is unlikely that North A frican countries would import substantial amounts of conventional energy from the EU. Countries in North A frica are also looking for ways of decarbonizing their systems. M oreover, their markets are plagued by the lack of a regulatory framework for trading energy with foreign countries. Currently, only the incumbent operator can import energy, subject to restrictive conditions. Even if reforms are introduced, with real energy markets being set up and opened to competition, large-scale deployment of renewable resources would in fact make available sufficient energy resources to satisfy local demand.

To assess the optimal regulatory framework, our regulatory analysis, starts with diagnosing the current situation and identifying the main obstacles to integration. We propose various ideas for regulatory adaptation, with regard to a range of possible governance structures. Regulatory analysis completes the study by highlighting how potential risks for the corridors should be managed and how potential revenues should be shared among partners in the corridor scheme.

\section{New Institutional E conomics analysis of the electricity corridors}

In this section, we assess potential revenue and the risks faced by stakeholders in the corridors. We also determine the optimal framework for the contractual arrangements governing the corridors. We focus in particular on the extent to which investments are mutually dependent and whether a long-term bilateral contract is required. Our analysis addresses (i) market and network risks and hazards, and (ii) the degree of asset specificity for the various investments. New Institutional Economics (NIE) has the potential to offer much insight to the energy sector. A pplications of the NIE to the electricity sector put into the light transaction costs that make contracts and norms incomplete and imperfect. Thus, 
such analyses look to the understanding of sectors dynamics and how to deals with international transaction, thus how to integrate different components of the coordination.

For the gas industry, it has been shown that in some cases, long-term contracts would provide a robust framework for protecting the interests of both up-stream and down-stream partners (Hubbard and Weiner 1991; Creti and V illeneuve 2004). For instance, Hallack and Glachant (2009) assesses longterm Take-or-Pay (TOP) gas contracts between Brazil and Bolivia from an NIE perspective and examine empirically the robust nature of the ToP framework over time. The case of an electricity corridor connecting the two sides of the M editerranean is an opportunity to apply this NIE perspective to the electricity industry and demonstrate how various partners can develop long-term contractual relationships. We conclude this section by assessing the need for a regulatory framework specific to corridor investment and renewable energy trade.

\subsection{An electricity corridor as a bilateral inter-dependent investment}

Investing in electricity corridors would be a first step toward full integration of the Mediterranean system over time. A M editerranean energy market for electricity would require substantial new investments and extensive market and institutional reforms to harmonize system integration as much as possible. To cope with such complexity, one solution would be to adopt a "corridor-by-corridor" approach rather than an all-encompassing approach, which seems impossible under current structure. Our analysis treats the electricity corridor project as a typical case of bilateral inter-dependent investment (N eumann and V on Hirschhausen (2006); Hallack and Glachant (2009)). Neither the new investor in renewable energy nor the investor in the interconnector would commit themselves to investments unless the other market player agreed to do the same; that is, an investment by only one actor would be of no value unless the other actor made a reciprocal commitment.

To illustrate this mutual dependence, we consider two extreme scenarios to analyze the feasibility of the project if only one investment is undertaken. In the first scenario, let us suppose that only the interconnector will be built. The current installed generating capacity in N orth A frican countries is just sufficient to meet domestic demand ${ }^{10}$. We cannot expect export potential from $N$ orth A frica to the EU,

\footnotetext{
${ }^{10}$ In 2010 we recorded total installed capacity of 3,600 M W in T unisia, whereas local peak demand reached 3,000 M W for several hours in the year.
} 
at least in the short run. Similarly, energy exports in the opposite direction are not profitable. Indeed, under the current legal frameworks in Tunisia and Algeria, for instance, energy companies are not allowed to import energy unless the Ministry of Industry finds that it will not alter the domestic market ${ }^{11}$. Nor are foreign companies are allowed to enter $\mathrm{N}$ orth A frican markets freely. In short, there is no energy market open to trade in the region. Under these circumstances, an interconnector is pointless and would be of no benefit to the investor.

In the second scenario, let us assume that a huge amount of renewable generating capacity will be built. The small size of North African systems and the monopolistic structure of their transmission system ${ }^{12}$ would limit the technical and commercial feasibility of injecting a large amount of renewable energy from the new capacity into North A frica's home market. Though a small amount of renewable energy could be fed into the local system, other buyers located outside the region would be needed to justify the substantial investments required to realize North A frica's full renewable-energy supply potential.

A joint investment in additional generating capacity, devoted mainly to the export market, along with the interconnection line, is thus essential for the profitability of the overall project. In the absence of this dual investment, the overall project will not be viable. We can compare the transmission from North A frica to the EU to a market in which a single generator has power available to inject into a single transmission line. In this case, the new renewable power plant in North A frica would mainly deliver production to the EU market through the proposed corridor.

\subsection{Arguments for long-term contracting: analysis of risk and revenue alignment}

From an economic point of view, this bilateral dependence requires an ex-ante long-term, contractual commitment. Concerns about bilateral dependence in contractual arrangements are based on transaction-cost economics (J oskow 1985). NIE asserts that long-term contracting that minimizes the transaction costs of contracting partners can safeguard the interests of both up-stream and downstream partners (Neumann and Hirschhausen 2006). Transaction costs rise to the extent that one or both parties must make transaction-specific sunk investments or if either party lacks credibility in

\footnotetext{
${ }^{11}$ TSOs are integrated and state-owned in N orth A frica. For Tunisia, see B en A rfa (2008).

${ }^{12}$ In Tunisia, STEG owns about $85 \%$ of total generating capacity and fully owns and operates the transmission and distribution networks and electricity supply (Ben Arfa, 2008).
} 
satisfying ex-ante commitments. These problems explain why more complex institutional arrangements may be required.

\subsubsection{L evel of risk}

In general, in an upstream-downstream or vertical transaction, risk and uncertainty can be significant. Contractual risk rises when the obligations of the partners and the solutions to possible contingencies cannot be explicitly stated for every possibility, which in turn increases the likelihood of a problem with ex-post performance or opportunistic behavior by the agent (Hallack and Glachant 2009). Contractual arrangements should be made in such a way as to minimize ex ante the risk of opportunistic behavior which could arise ex post (J oskow 1987).

The transaction between the new renewable energy producer and the interconnector developer has two main components subject to market risks. The first is the price differential between the two markets, which should attract energy exports to the EU market and inform calculation of the interconnection capacity price. The second relates to the capacity rights or volume of electricity flows over the interconnector that the new producer is able to obtain. We can thus identify and analyze two kinds of risks: price-differential and volume.

\subsubsection{Price differential risk}

Due to the absence of open electricity markets in North A frica, flows over the new line would be driven by the margin between wholesale market prices in the target EU market and the production costs of the new renewable power plant. Economically speaking, it would be worthwhile to export energy from $\mathrm{N}$ orth A frica to the $\mathrm{EU}$ if the cost-price margin covers at least transmission costs plus the export-access tariff ${ }^{13}$. This risk thus has two components: wholesale electricity price trends in the EU and the total cost of the new renewable power plant.

Uncertainty about electricity price trends in the EU is generally low, but cannot be completely ruled out. For instance, the long-term Italian market price for baseload power plants was estimated at $€ 70$ per M Wh, while the recorded trend in national prices in 2008 and 2009 varied between $€ 50$ per $\mathrm{MWh}$

\footnotetext{
${ }^{13}$ Since the interconnector involves a non-EU country, interconnector user(s) wishing to inject energy into the EU system must pay an export fee designed to cover the cost of using the EU network.
} 
and $€ 95$ per $\mathrm{M} \mathrm{Wh}$ In the long term, Italian wholesale electricity prices are likely to deviate from those currently observed (AEEG, 2010)..

Regarding the total cost of renewable energy, it is worth noting that such costs are generally higher than fossil or nuclear energy. Moreover, substantial investment is still required to advance various renewable technologies. Once installed, solar or wind plants operate at zero marginal costs, a clear market advantage compared to other energy sources. However, if we compare the total cost of building and operating a new power plant to forecasts of annual electricity output, renewable technologies look less attractive ${ }^{14}$. Compared to traditional power plants, renewable generators are cheap to run but costly to build, which makes them particularly vulnerable to changes in the cost of capital. Renewable energy is also variable and unpredictable. Such characteristics make its unitary hourly cost very high, a major disadvantage in terms of competitiveness ${ }^{15}$. Finally, a more fundamental challenge is that renewable generators also entail costs for the wider electricity grid. The best sites for utility-scale projects are often far from big cities, which adds to transmission costs.

If one assumes that a new power plant must pay capacity rights for using the interconnector equal to at least the cost of the line, there is a risk that the forecast cost-price margin will fall below the capacity price plus export access tariff (Cuomo et al. 2012). The downstream partner also faces a pricedifferential risk, mainly because the congestion revenues that would inform capacity-right calculations will be used to cover the cost of investing in and operating the new interconnector.

\subsubsection{Volume risk}

Both up-stream and down-stream partners face a volume risk. For the producer of new renewable energy, there is a high risk of not being able to dispatch power to the EU market. Current EU regulations provide neither priority access to the network nor priority of dispatch for renewable energy generated outside of the U nion. The interconnector owner would also face the risk of unused capacity, closely related to the volume risk faced by the up-stream partner. Because the interconnector would be designed to allow the renewable power generator to trade on the EU market, any obstacles would have

\footnotetext{
${ }^{14}$ W e note that renewable technologies are currently strongly incentivized in Europe. B ut the duration of these incentives are ambiguous in the long term. $M$ any countries are reviewing the premiums given to renewable energy and there is no clear guarantee about their persistence in the long term.

${ }^{15} \mathrm{M}$ any EU counties are introducing capacity-payment instruments to make such technologies more attractive.
} 
a knock-on effect on flows through the interconnector. The volume of flows through the interconnector should be allocated in such a way as to guarantee interconnector revenue in the form of a flow-times-capacity-price high enough to cover interconnector costs and avoid revenue clawback.

\subsubsection{A sset specificities of the electricity corridor}

A sset specificity is usually defined as the extent to which an investment made for the purpose of a particular transaction cannot be re-deployed to other transactions (J oskow 1987). Given the bilateral investment characterizing the project, we can assume that the investment in new generating capacity assets is highly specific and dedicated; the investment in the interconnector displays both site specificity ${ }^{16}$ and dedicated asset characteristics.

New renewable energy generating capacity of several gigawatts would represent a large share of electricity demand in a North African country. Several megawatts could be directed to the local market, but the remaining capacity would be dedicated to exportation to the EU market. The lack of cross-border infrastructure linking North African countries rules out other alternatives for selling power. This means that the investment could not be made without some guarantee of selling a significant volume of energy to customers in the EU. If the up-stream partner decided to terminate the contract prematurely, for instance by not building the interconnector or not offering sufficient capacity rights to the producer, it would leave the producer with excess capacity, unlikely to be utilized in the N orth A frica market, at least in the medium term. In order to enter the EU electricity market, the investment would not only require interconnection infrastructure to be built but also a bilateral contractual commitment from an EU retailer. The degree of asset specificity and dedication depends on the amount of energy contracted with the producer and consequently on the scale of investment in generating capacity. The greater the contracted quantity, the more difficult it would be to rapidly dispose of new partners at a compensatory price. Due to the capital intensity of the power plant, greater allowance must be made for the dedicated asset in order to negotiate longer contracts.

Similarly the investment in the interconnector is a specific dedicated-asset investment. In the medium term, given market conditions and regulatory constraints, it is unlikely that energy will be exported from the EU to North Africa or vice versa. This would also be a site-specific investment.

\footnotetext{
${ }^{16}$ Site specificity is when allowance is made for location when planning and creating the investment decision.
} 
Traditionally, the main reasons for investing in new transmission infrastructure are to link generation to load and enhance system reliability. Liberalization has made transmission planning much more difficult. In an integrated monopoly structure, planning and investing in generation and transmission were coordinated. Today, the decision to generate is taken by individual companies and the TSO may own the transmission asset while subcontracting to independent operators. Developing new generating plants and connecting them to the transmission network raises additional challenges for optimal transmission planning. The location of the line depends on the location of the new power plant. Once sited, the interconnector is immobile. Thus, the interconnector should be developed simultaneously with the power plant itself. This appears to be a classic case of a "cheek-by-jowl" relationship (Williamson, 1981).

\section{Results and discussion}

\subsection{L ong-term contracting to coordinate investment in bilaterally dependent corridors}

As seen in the previous section, price-differential and volume risk would affect the interests of both partners. It makes sense to allocate risk to the party best able to manage it. That ability depends on the ease with which the partner can obtain relevant information about the market environment and how quickly it can respond to unexpected changes in market conditions. It can be assumed that the EU based TSO has more information on price formation in the EU market, and also on real and potential final demand and consumer sensitivity to price changes. In contrast, the operator of the renewable power plant would have more information on production and opportunity costs. Efficient sharing of market risk would involve allocating the management of EU market price risk to the TSO and the management of cost risk to the generating company; both partners, however, should jointly manage volume risk.

The presence of transaction-specific investments gives rise to ex-post opportunistic problems if the partners have to rely on repeated bargaining games. In the short and the medium term, both partners have aligned interests for undertaking the transaction. It is beneficial to the producer to enter the EU electricity market for economic reasons. Similarly, the EU TSO, acting on behalf of EU consumers, would stand to gain from such a project. However the partners in the corridor project would have high incentives to unilaterally stop the contract when their interests start to diverge in the long term. This 
risk is large if one partner would gain by taking action that does not maximize the joint profit of the partners or jeopardizes the interests of the other partner compared to its ex-ante estimate of transaction benefits (J oskow, 1983). For instance, a long-term shift in market conditions or energy legislation in N orth A frica might enable the producer to serve several contracts, instead of being wholly tied to the EU market. Such a shift would create opportunities for the producer to exercise its monopolistic power either through a change in trading partner or by raising the cost of negotiations with its existing partner in order to maximize rent from a re-negotiated contract. Likewise, the downstream partner might enjoy similar opportunities if market and regulatory conditions evolved to allow more trading companies to contract for capacity rights over the interconnector. Maintaining good relations between the parties requires some flexibility in the provisions of the contract, but the governance structures of the contract must be settled ex ante to reduce the incentives for opportunistic behavior.

\subsection{Contractual duration and credibility}

In the following we identify the three steps for implementing the long-term contract.

\subsubsection{The first step in establishing the contractual relationship: ex-ante investment phase}

In this first phase, "self-enforcement", supported by alignment of the long-term interests of contract partners, acts as a powerful incentive for them to develop the infrastructure for their future trade. Selfenforcement, defined in theory as a type of security to back the credibility of a contractual arrangement, is motivated by the shared goal of the partners to simultaneously develop both infrastructures. To achieve this, the contracted prices and volumes must be negotiated ex ante and signed prior to undertaking the investments, in order to provide the incentives for developing the project while guaranteeing ex-ante a return for both parties. Due to the presence of specific assets, firm trading targets, both in volume and price, must be set in line with a fair sharing of project risk ${ }^{17}$.

\subsubsection{The second step of the contract: energy trade through the interconnector}

During this second period, both infrastructures are in place. B oth parties would still have a strong interest in developing all of the activities related to the contractual agreement and fulfilling their exante commitments. "Hostage clauses," as a source of self-enforcement, would create long-term

\footnotetext{
${ }^{17}$ We have not considered the calculation of optimal volume and price targets; this would require cash-flow analysis of both investments, beyond the scope of this paper.
} 
alignment around contract implementation in this phase (Coase, 1972). Both partners would have al ready made the initial investment. Each contract partner must rely on the action of their counterparts to cover up-front investments. Moreover, due to the presence of scale economies in generation and transmission infrastructure construction, a substantial delay may be expected between the initial investment and the first returns. Hostage clauses play a part in underpinning the credibility of the contractual arrangement at this step, until at least one partner covers its investment costs and starts showing "good" profits. But it is the price-quantity mix for each party, fixed ex ante in the contract clauses and linked to foreseeable market trends, that determines when project costs start to be recouped.

\subsubsection{The third step of the contract: enforcement risk}

This step would take place if contingencies arise in the future, negatively altering implementation of the contract as defined ex ante; or leading to its premature termination. A s an example we can consider the threat of regulatory or political changes. Energy infrastructure projects outside the EU present political risks. This is especially true in Tunisia, for instance, where the government started major reorganizing after the revolution in Spring 2011. Political risks there now include a lack of transparency in the framework for investment as well as ongoing risk of changes to the fiscal, tax, and/or legal environment once the investment has been made.

Setting aside any regulatory or political considerations, the interests of the contracting partners could be misaligned. One or both parties could have incentives for opportunistic behavior that could jeopardize contract implementation or lead premature termination. M onopoly power could motivate partners to renegotiate the distribution of the economic quasi-rents defined by the initial contract (in terms of price and volume clauses) and to threaten cutting off supplies to force a modification of the contract. The presence of other partners capable of advantageously replacing the initial partner would sustain this incentive.

Although the long-term alignment of partners' interests provides a robust safeguard for contractors through self-enforcement (at least until project capital has been recouped), an ex-ante plan for thirdparty enforcement should be in place to ensure continuation of the contract according to terms. In general, the legal system assumes this role. 


\subsection{G overnance structure and regulatory constraints}

We end this analysis by evaluating the regulatory framework specific to investment in renewable energy infrastructure, wholesale trade, and grid integration in the two regions. In particular, we question whether the regulatory framework needs to be adapted for such corridors to be feasible. We look at two types of corridor: a back-to-back corridor where the vendor and client countries are neighbors and a transit corridor in which an intermediate transit country would enable transmission of renewable power. We recommend changes to the regulatory frameworks in the involved regions based on the type of corridor. For the governance structure, we consider merchant, regulated, and hybrid approaches.

\subsubsection{Back-to-back corridor}

Considering the first corridor scenario where the company generating renewable energy is located in a North African country near an EU destination country (Figure 1). Possible corridors would link Tunisia to Italy or A Igeria to Italy.

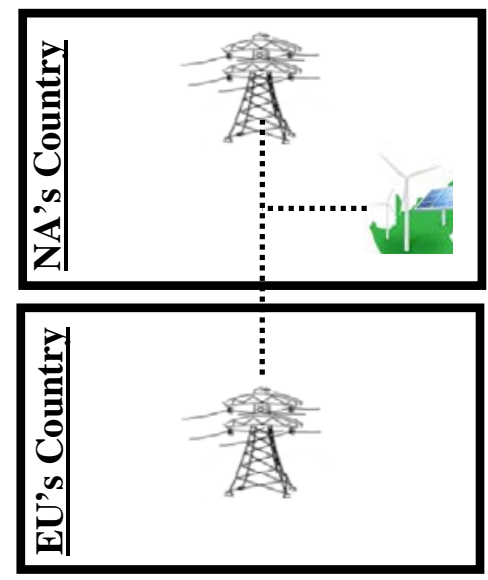

Figure 1. Back-to-back corridor

\subsubsection{M erchant approach: closed private long-term contract}

Under a merchant scheme, an investor that is legally separate from the TSOs in the interconnected markets applies to the national regulatory authorities and the European Commission for an exemption from the regulatory framework. A project that meets the conditions for eligibility set forth in the regulation may be granted full or partial exemption from any or all restrictions on the use of congestion revenues, regulated third-party access, ownership unbundling, and tariff regulation. The 
project may not be funded by transmission tariffs, and investors would enjoy the full risk and full reward of the market. Under this approach, we can assume that up-stream and down-stream partners may prefer to fully "internalize" all the risks and the revenues of generation, transmission, and supply of renewable energy in a closed, private, long-term contract. This is the "merchant" corridor approach. The generating plant could be owned and operated by public companies, but also by private or foreign investors. Under this approach, the producer will tie all the renewable energy generated for the EU market to the new interconnector. The specificity of renewable energy requires priority access over the interconnector and on the destination network. In the first case, priority access is guaranteed under the Iong-term contract with the interconnector owner. In the second case, the EU destination regulator would need to treat the foreign (non-EU) renewable energy in the same way as local resources and give it priority access. Finally, a bilateral long-term supply agreement with a targeted price should constitute the second hedging component for the renewable energy producer under this merchant configuration.

Regarding recovery of interconnection investment costs, capacity rights over the line should be sold on a long-term basis for targeted volume and price, while providing the priority access required by the generator. However, if the owner is a private investor, it is unlikely that priority access to the downstream network will be guaranteed.

On the EU side, under this regime, the renewable energy supplier would also require a long-term supply agreement with a target quantity. Detailed analysis and forecasting of renewable energy availability and potential generation quantity would be required to determine the contractual volume of renewable energy. EU generators of renewable energy al ready enjoy priority access to the network and special sales tariffs that include an incentive component (such as feed-in-tariffs or feed-in-premiums). If a generator of renewable energy operating outside the EU were treated like a local one, there would be no need to have a special long-term renewable energy supplier as a partner. The TSO in the EU country would have the task of integrating the renewable energy generated abroad. This would of course depend on the degree of involvement of the EU-based TSO in the corridor. If the EU-regulated TSO is not involved in the project, it is hard to envision a particular integration regime.

\subsubsection{Regulated approach: classical scheme}


A regulated approach means that the business models of the partners in the corridor project will be designed to suit the current regulatory framework in the countries involved. In some areas of the corridors, this may constrain the ability of the partners to manage freely the risks involved in the project. Generally, under a regulated investment scheme, a TSO develops and operates interconnectors to be included within its regulated asset base. A $\mathrm{n}$ interconnector developed and operated under a regulated investment scheme may recover costs via revenue from national transmission tariffs. The interconnector must also follow the requirements of the regulated system within which it is developed and operated.

Under this approach, we assume that the partners would dissociate the risk and revenue related to transmission from those associated with up-stream renewable-energy generation or with downstream supply. On the EU side, the interconnector would be the responsibility of the EU-regulated TSO, which would operate it in compliance with its national regulations. The EU TSO in the destination country would act as a transit TSO at the EU border. It cannot share the risks and revenues of generating and supplying renewable energy. This means that it will manage the interconnection line under a regulated transit scheme at its own risk and with its own revenue, thus operating separately from both up-stream generation and down-stream supply. There can be no certainty that the TSO will treat the renewable energy flows on its grid as "RES priority" for connection, dispatch, and congestion. Doing so seems likely, however, as long as these resources are certified by the TSO as "truly RES" despite being of foreign origin.

The main disadvantage of this regime relates to capacity rights allocation. EU regulations prohibit any long-term allocation of capacity rights over a transmission line unless an exemption is obtained from the Commission. Moreover, this regime presents a high risk of non-use that the owner of the interconnection will not be able to hedge ex ante, since rights over the line, constituting the main means of covering costs, must be sold in the short run under third-party access rules.

Regarding the generation of renewable energy, the legislative framework applicable to electricity in North A frican countries restricts energy exports by private companies. It is probable that only the vertically integrated utility (VIU) will be allowed to make such investments, since they are intended 
for export ${ }^{18}$. Furthermore the interconnector on the North A frican side will be owned and managed by the local VIU. The extent to which the renewable-energy generator will have priority access to the interconnection line would depend on how much say the North African VIU has in how the interconnector, jointly owned and managed with the EU partner, is shared. But on the contrary, there would be no priority access to the EU network and market. The trade-off between these two kinds of risks would be decisive for determining the optimal sharing rule between the two TSOs over the interconnector.

Finally, as with a merchant approach, the supply of renewable energy will be slightly affected by the governance structure in the up-stream and down-stream sections of the chain. From an economic point of view, a long-term supply agreement would be more appropriate and the extent to which foreign renewable energy of this sort will be treated as "local" will weigh on the need for long-term supply contracting.

\subsubsection{Hybrid approach: hybrid contractual scheme}

The two preceding regimes can be seen as two distinct, yet feasible cases, from the NIE and regulatory perspectives. The merchant approach is closer to NIE theory but would require substantial regulatory change on both sides of the Mediterranean. However, despite being less efficient in economic terms, the second case stands a better chance of becoming operational because it fits the current regulatory regime

W e propose an intermediate or hybrid approach, combining the two regimes with focusing on the main form of leverage for realizing the renewable energy project, which is priority access to the interconnector and the EU grid. First, to guarantee priority access to the EU network, the corridor infrastructure should be owned and managed by the EU TSO and subject to a regulated regime. Second, priority access to the interconnector could be obtained under an exemption procedure allowing capacity rights to be sold on a long-term basis. EU regulations allow for some exemptions if, among other reasons, it can be demonstrated that the investment would not be viable without the

\footnotetext{
${ }^{18}$ Current regulation in N orth A frica barely recognizes foreign investment in generating capacity. It is strictly forbidden in Tunisia, possible but restricted in A Igeria.
} 
benefit of the exemption ${ }^{19}$. Such exemptions only apply if the countries involved are in the EU. This is why an EU regulatory framework recognizing the North A frican partnership is strongly recommended. As long as the interconnector remains a regulated investment, capacity rights are exempt from the short-term allocation constraint. The bilateral dependence between the renewable-energy investment and the corresponding transmission clearly justifies the need for a long-term contractual arrangement, providing that substantial imports of renewable energy from $\mathrm{N}$ orth A frica can be achieved.

Under a hybrid approach, the economic insights gained from this sort of project correspond to the recommendations of transaction-cost theory. Only limited regulatory adaptation would be needed. In Table 1 we summarize the feasibility of the three regimes with regard to their economic incentives and the regulatory changes required.

\begin{tabular}{|c|c|c|c|c|}
\hline & \multicolumn{2}{|c|}{ Economic Incentives } & \multicolumn{2}{|c|}{ Regulatory Framework } \\
\hline & R isk M anagement & Priority Access & Governance & $\begin{array}{l}\text { Regulatory } \\
\text { Adaptation }\end{array}$ \\
\hline $\begin{array}{l}\text { M erchant } \\
\text { Corridor }\end{array}$ & $\begin{array}{l}\text { Risk aligned with } \\
\text { revenue }\end{array}$ & $\begin{array}{l}\text { Only to the } \\
\text { interconnector }\end{array}$ & Private ownership & V ery High \\
\hline $\begin{array}{l}\text { Regulated } \\
\text { Corridor }\end{array}$ & $\begin{array}{l}\text { High risk for } \\
\text { corridor partners }\end{array}$ & Only to the network & $\begin{array}{l}\text { VIU in N. Africa, } \\
\text { TSOs in EU }\end{array}$ & V ery Low \\
\hline$\frac{\text { Hybrid }}{\text { Corridor }}$ & $\frac{\text { Risk aligned with }}{\text { revenue }}$ & $\begin{array}{l}\text { Priority access to } \\
\text { both interconnector } \\
\text { and network }\end{array}$ & $\begin{array}{l}\text { VIU in N. Africa, } \\
\text { TSOs in EU }\end{array}$ & Low \\
\hline
\end{tabular}

Table 1. Pros and cons of the three back-to-back corridor regimes

\subsubsection{Transit corridor}

W e now address a second possible corridor scenario in which an EU frontier-country acts as a point of transit between the North A frican renewable energy-producer and the EU destination country. For example, a corridor of this sort could transit via Spain, on its way from M orocco to France ${ }^{20}$.

Two situations can be distinguished (see Figure 2). In the first case, we can assume that the transit country will just see a transmission line connecting the downstream and the up-stream countries, passing across its territory, without connection to its own network. This is a more expensive option,

\footnotetext{
${ }^{19}$ Generally, Regulation (EC) No 714/20094 and Directive No 2009/72/EC promote investment in electricity interconnectors within a regulated access regime. Exceptionally, to allow for the development of interconnectors on a voluntary basis, the regulation provides for exemptions from the regulated-access regime when a project's risk level is judged to be prohibitive to investment.

${ }^{20}$ Overall $23 \%$ of Spain's electricity was generated from wind and solar in 2010. It is the world's third biggest producer of wind power. Unlike Italy or France, Spain would have little to gain from importing renewable energy from $\mathrm{N}$ orth A frica.
} 
that does not involve any alteration or modification in the transit network; the imported renewable energy flows are isolated from the network flows in the transit country. This situation can be called a "line-transit corridor" scenario. In the second case, a less costly configuration would involve first injecting the renewable energy into the transit network, then sending it to the destination country. This solution is known as a "network-transit corridor" scenario.

As above, we consider the three kinds of corridor regimes: merchant, regulated, and hybrid. However we focus only on the transit country. The analysis of the up-stream and down-stream countries is ignored here since we expect the same insights as for a back-to-back corridor.

\section{Line-T ransit Corridor}
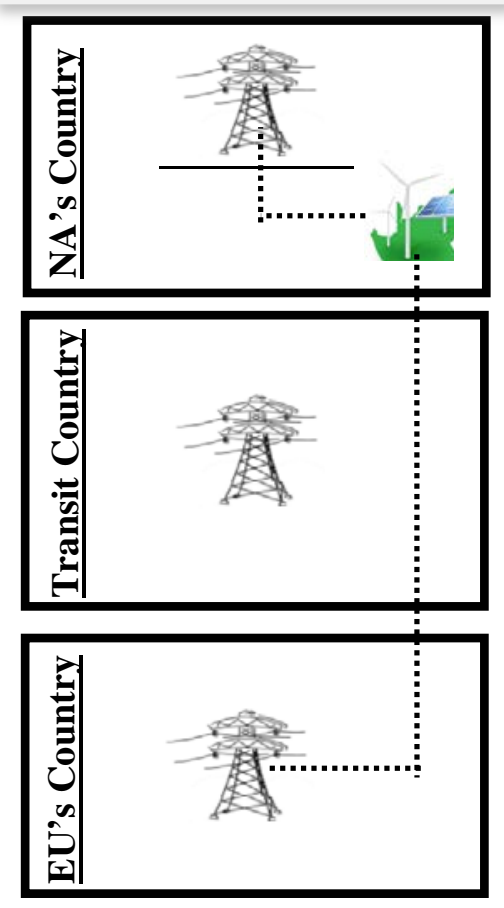

\section{Network-Transit Corridor}
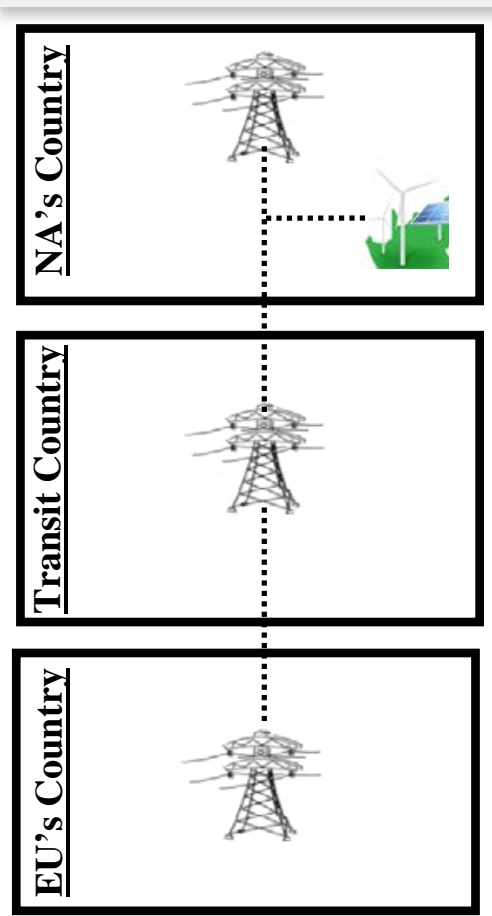

Figure 2. Line-Transit Corridor vs N etwork-T ransit Corridor

\subsubsection{Line-transit corridor scenario: hybrid-transit contract}

Under this initial scenario, the transit country would act a passive player. Under national regulations in EU countries, a transmission line cannot be owned by an organization other than the national TSO. We may thus assume that if a merchant approach is chosen, the TSO of the transit country would own the infrastructure. Specific regulations for a transmission line of this sort would nevertheless be required, as it would be disconnected from the national network. So far, there has been no clear attempt in the 
EU to consider network configuration of this sort. Assuming that the regulatory framework in the transit country would be favorable to investment in isolated lines, the corridor partners (including the transit-transmission owner), would manage the investment risks in the same way as under a back-toback corridor scenario. It would rather sell the capacity rights over its transit line on a long-term basis for targeted volume and price, while providing the priority access required by the renewable energy producer. The infrastructure owners in the three parts of the corridor would need to obtain RES certification.

Under a regulated approach, the transit-transmission owner, even if isolated from the network, would have to manage the risks involved just like any other conventional line, with revenues regulated and no scope for selling capacity rights under a long-term bilateral agreement. A scheme of this sort would once again pose the problem of priority access for renewable-energy producers, much as in the other parts of the interconnector. Moreover, the transit TSO would gain nothing from socializing interconnection-line costs to its consumers without seeing any economic or social benefit from the project.

Here again we would advocate a hybrid approach, which would provide some flexibility regarding the contractual arrangement for allocating capacity rights to transit-line users. Although the current regulations clearly ignore specific transit lines of this sort, it is important to bear in mind that the isolated line could still be treated as an interconnection by the transit country. This would justify applications for exemption from the short-term allocation condition applicable to capacity rights. The recommended design for the transit corridor would involve a hybrid approach allowing for long-term allocation of transit-line rights, in parallel with a long-term allocation of interconnector rights on the both sides of the transit country, the aim being to improve economic attractiveness by guaranteeing investment returns, with less need for regulatory changes.

\subsubsection{N etwork-transit corridor scenario: private long-term transit contract}

Under this scenario, renewable-energy flows would go through the transit network before being injected into the destination system. We can expect that beyond a certain volume of flows, the network in the transit country may need to be reinforced in order to accommodate the additional energy. A 
third product, in addition to energy and the interconnection infrastructure, is necessary for transitcorridor feasibility.

W ith a merchant transit scheme, the TSO in the transit country would externalize the cost of grid reinforcement to the up-stream and down-stream players. Moreover it would prefer a form of longterm contract to secure stable access to transmission. With this contractual arrangement, priority access through the transit country is unlikely to be refused, as long as it does not upset system balancing. However, if a regulated allocation of capacity rights is chosen, it is more likely that it would refuse to give full priority-access rights to the renewable-energy transit flows. Indeed, it may try to treat them as standard transit flows.

Under a hybrid approach renewable-energy transit flows would be treated in the same way as any other conventional energy in transit, with the revenues regulated. On the other hand, the same priority access would be given to any renewable-energy flows transmitted over the system. It has to be acknowledged that there is a very low likelihood of this scenario being realized, given no economic or social benefits to justify the transit TSO taking such measures.

We summarized the feasibility of the three regimes for the two transit scenarios in Table 2 with regard to economic incentives and regulatory framework. It is emphasized that if a line-transit scenario were to be adopted, a hybrid corridor would again be the most efficient option in terms of risk management and the allocation of priority access to renewable-energy flows. Furthermore, there would be less need for regulatory change. However, a hybrid approach is unlikely to be adopted in a network-transit scenario. A merchant approach, with stable allocation of transit rights, is preferable even if all of the partner countries need to change their regulatory framew orks. 


\begin{tabular}{|c|c|c|c|c|c|}
\hline & & \multicolumn{2}{|c|}{ Economic Incentives } & \multicolumn{2}{|c|}{ Regulatory Framework } \\
\hline & $\begin{array}{l}\text { Transit } \\
\text { Country }\end{array}$ & $\begin{array}{c}\text { Risk } \\
\text { Management }\end{array}$ & Priority Access & Governance & $\begin{array}{l}\text { R egulatory } \\
\text { A daptation }\end{array}$ \\
\hline \multirow{3}{*}{$\begin{array}{l}\text { Line- } \\
\text { Transit } \\
\text { Corridor }\end{array}$} & $\begin{array}{l}\text { M erchant } \\
\text { Corridor }\end{array}$ & $\begin{array}{l}\text { Risk aligned with } \\
\text { revenue }\end{array}$ & $\underline{\text { Yes }}$ & Private owners & Very High \\
\hline & $\begin{array}{l}\text { Regulated } \\
\text { Corridor }\end{array}$ & $\begin{array}{l}\text { High risk for } \\
\text { corridor partners }\end{array}$ & No & $\begin{array}{l}\text { Transit country } \\
\text { TSO }\end{array}$ & Very Low \\
\hline & $\frac{\text { Hybrid }}{\text { Corridor }}$ & $\begin{array}{l}\text { Risk aligned with } \\
\text { revenue }\end{array}$ & $\underline{\text { Yes }}$ & $\begin{array}{l}\text { Transit country } \\
\text { TSO }\end{array}$ & Low \\
\hline \multirow{3}{*}{$\begin{array}{l}\text { Network- } \\
\text { Transit } \\
\text { Corridor }\end{array}$} & $\begin{array}{l}\text { M erchant } \\
\text { Corridor }\end{array}$ & $\begin{array}{l}\text { Risk aligned with } \\
\text { revenue }\end{array}$ & $\underline{\text { Yes }}$ & Private owners & High \\
\hline & $\begin{array}{l}\text { Regulated } \\
\text { Corridor }\end{array}$ & $\begin{array}{l}\text { High risk for } \\
\text { corridor partners }\end{array}$ & No & $\begin{array}{l}\text { Transit country } \\
\text { TSO }\end{array}$ & Very Low \\
\hline & $\begin{array}{l}\text { Hybrid } \\
\text { Corridor }\end{array}$ & \multicolumn{4}{|c|}{ Very unlikely } \\
\hline
\end{tabular}

Table 2. Pros and cons of the various transit corridors regimes

\subsubsection{The prospects for a super grid}

Three factors should be considered before embarking on a regional super grid connecting the two shores of the M editerranean. The first factor would be the degree of network integration between the two shores. Integration in the form of electricity corridors could start with simple back-to-back corridors, developing in the long term into multiple transit corridors (in which various countries would be involved) and enabling very remote markets to be reached. Second, market integration would also be an important condition for building a super grid. In the short term, power-to-market integration seems a more plausible configuration. Given the lack of an electricity market in North A frica, the first projects are more likely to entail integrating renewable power plants located in a third country into the EU electricity market. In the long term full market integration is foreseeable once North A frican countries have made the necessary reforms to open their markets to trade and expand the potential for investment in renewable energy.

In Figure 3 below we highlight some market and regulatory prerequisites necessary for meeting the three conditions discussed above. From a short-term perspective, the framework would involve powerto-market integration, via back-to-back corridors, with the aim of achieving some investment in renewable power plants and trade. This configuration would not require a major change in the regulatory framework, except for regulatory treatment of renewable resources on both sides of the Mediterranean. Exporting renewable energy from North Africa would also raise special issues. Regulation would need to facilitate long-term contracting for electricity trading via the corridors, as a 
first step toward regional integration. In the medium term, to attain a moderate level of renewableenergy trade, we would expect investments to reinforce existing networks in all the parts of the corridors, including those located in transit countries. Clear, workable regulations specific to renewable energy are also required. In particular, A rticle 9 of the 2009 's renewable energy directive ${ }^{21}$ should be modified to recognize imported renewable energy similar to output from other EU renewable plants. The EU directive must provide incentives to invest in renewable energy south of the M editerranean and make allowance for joint projects with third countries. Setting up a M editerranean association of TSOs, like ENTSO-E ${ }^{22}$ in Europe, would facilitate cooperation and harmonization of transmission rules among the M editerranean countries involved. In the long term, in order to trade significant amounts of large-scale renewable energy, multiple transit corridors could be pursued. Integration would be market-to-market, meaning that structural reforms would be needed in North A frica to legally restructure electricity markets to provide for unbundling and trade. A new win-win regulatory framework is needed to make it easier to harmonize rules and protect the interests of both regions with regard to the optimal management and use of energy resources. The EU should institutionalize wholesale energy trade with North Africa, based on a new Mediterranean Energy Community.

\footnotetext{
${ }^{21}$ Directive 2009/28/E C of the European Parliament and the Council of 23 A pril 2009 on promoting the use of energy from renewable sources.

${ }^{22}$ ENTSO-E is an EU association of TSOs interfacing with power-system users, EU institutions, regulators and national governments. Its activity contributes to security-of-supply issues, integrating renewable resources and orienting future EU grids.
} 


\section{GW S of RES energy potentially exchanged}

- Super Grid

- Unbundling in NA

- M arket O pening in NA

- New W in-Win RES Regulation

- Grid reinforcements

- Clear of RES regulation

- Changes to Article 9 of the EU renewable energy Directive

- Mediterranean ENTSO-E

- Limited regulatory change, except for RES

- Consideration of export in NA

- Long-term contracting

Figure 3. R egulatory adaptation given corridors' scenarios, market integration levels and the potential flows of RES

\section{Policy recommendations and conclusions}

Drawing on transaction-cost theory, this paper assessed business models for building a platform for wholesale trade in renewable energy among M editerranean countries via electricity corridors linking the two regions. We have used transaction-cost theory to assess alignment of the potential risk and revenue from such trade by identifying potential revenue, uncertainty, and risk for corridor stakeholders. Given market conditions in the short and the medium terms, and the current regulatory framew ork in North A frica, our first recommendation is that the new renewable power plant should be tied to the new interconnector and business via the line should be tied to the new generator. This means that the project can be seen as a typical case of bilateral interdependence. Second, to optimize risk-sharing between the parties and deal with possible problems of ex-post performance, a specific long-term contract should be implemented. It should grant the new generating capacity priority access to the line, specify a long-term supply agreement with the EU retailer for a target price, and provide 
for selling capacity rights for the interconnector to the new producer on a long-term basis and at a predefined price and volume.

A fter presenting the economic arguments regarding an efficient trading model for renewable energy, we assessed the regulatory framework specific to investment, trade, and integration in both regions. In particular, we question the need for adapting the regulatory framework as a prerequisite for realizing these corridors. Two kinds of corridors were studied: a back-to-back corridor (in which the North African source and EU destination countries are neighbors) and a transit corridor (in which an intermediate transit country would simply facilitate energy transmission). This second analysis yielded a key recommendation. A hybrid governance structure, requiring limited regulatory adaptation, seems to be the most efficient solution, regardless of corridor type, for facilitating investment in corridor infrastructure and conforming to the recommendation of transaction-cost theory. Finally, we should note that our analysis disregards financial considerations. Cost-benefit analysis would clearly be an important extension of this work, taking into account our regulatory recommendations, as some studies have already noted that these investments represent a great opportunity and should be stimulated ${ }^{23}$.

\section{Bibliography}

- AEEG. (2010), "Structure, prices and quality in the electricity sector" Annual Report, 2010 (http://www.autorita.energia.it/it/inglese/annual_report/relaz_annuale.htm)

- Battaglini, A., Lilliestam, J., Haas, A., \& Patt, A . (2009). “D evelopment of Super Smart Grids for a more efficient utilisation of electricity from renewable sources", J ournal of Cleaner Production, V ol 17, Issue 10, pp: 911-918.

- B en A rfa, 0. (2008). "Organisation de l'électricité en Tunisie : Situation actuelle et perspectives", M em-A Igeria Semina, 2008.

- Brancucci Martínez-A nido, C., L'A bbate. A., Migliavacca, G., Calisti, R., Soranno, M., Fulli, G., A lecu, C., de V ries, L.J. (2013). "Effects of N orth-A frican electricity import on the European and the

\footnotetext{
${ }^{23} \mathrm{Dii}$ (2012) has published a strategic study "Desert Power 2050" which has demonstrated that a super grid integrating Europe, N orth A frica and the M iddle East, on which almost $90 \%$ of traded energy would be renewable, is not just possible but would al so be beneficial for all the countries involved. The study demonstrates that a system of this sort would reduce electricity costs, contribute to environmental protection and reinforce energy security.
} 
Italian power systems: a techno-economic analysis", Electric Power Systems Research, Vol 96, pp:119-132.

- Brand, B ., \& Zingerle, J. (2011). “The renewable energy targets of the M aghreb countries: Impact on electricity supply and conventional power markets", Energy Policy, V ol 39, Issue 8, pp: 4411-4419.

- Bugaje, I.M . (2006). "Renewable energy for sustainable development in A frica: a review", Renewable and Sustainable Energy Reviews, V ol 10, Issue 6, pp: 603-612.

- Coase, R.H. (1972). "Industrial organization: A proposal for research", in Victor R. Fuchs, ed., Policy Issues and Research Opportunities in Industrial Organization, vol 3. New Y ork: National B ureau of Economic Research.

- Cuomo, M., Khalfallah, H., Rubino, A., \& Glachant, J.M . (2012) "A legal and Economic analysis of the proposed Italian-T unisian Electricity Interconnector", R eport for TERNA.

- ENTSO-E. (2014) "Statistical Factsheet 2013", ENTSO-E Report.

- Dii. (2012) "Perspectives on a sustainable power system for EU M ENA", Dii Report.

- Glachant, J.M ., \& Hallack, M. (2009). “Take-Or-Pay Contract Robustness: A Three Step Story Told by the Brazil-B olivia Gas Case?", Energy Policy, V olume 37, Issue 2, pp. 651-57.

- Joskow, P. (1985). "V ertical integration and long-term contracts: The case of coal-burning electric generating plants", J ournal of Law, E conomics and Organization, V ol 1, No 1, pp:33-80.

- Joskow, P. (1987). "Contract duration and relationship-specific investments: Empirical evidence from coal markets", Vol 77, No 1, The A merican Economic Review.

- K omendantova, N., Patt, A., Barras, L., \& Battaglini, A. (2012).“Perception of risks in renewable energy projects: The case of concentrated solar power in North Africa", Energy Policy, V ol 40, pp: 103-109.

- Neumann, A . \& V on. Hischhausen, C. (2006) “L ong-term contracts and asset specificity revisited A n empirical analysis of producer-importer relations in the natural gas industry", Center for energy and Environmental Policy Research, 06-010 W orking Paper.

- Williamson, O.E. (1983). "Credible commitments: U sing hostages to support exchanges", A merican Economic Review,73, pp:519-540. 